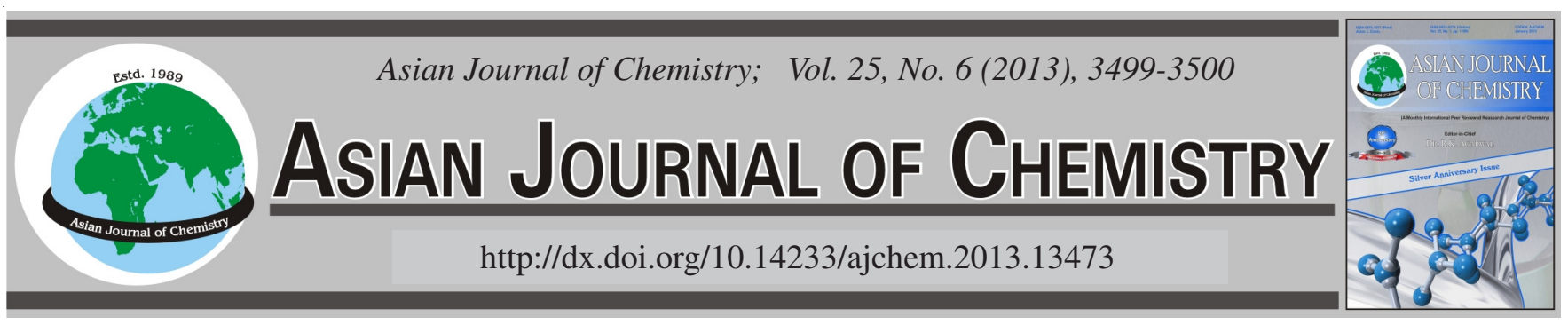

NOTE

\title{
Synthesis of 3-Vinylphenyl Ethyl(methyl)carbamate: A Potential Human Metabolite of Rivastigmine
}

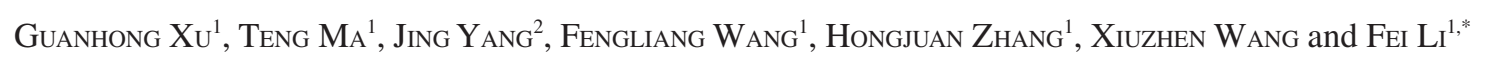

${ }^{1}$ School of Pharmacy, Nanjing Medical University, Nanjing 210029, P.R. China

${ }^{2}$ Chireach Biomedical Technology (Group) Co., Ltd., Suzhou 215128, P.R. China

*Corresponding author: Fax: +86 25 86863165; Tel: +86 25 86863175; E-mail: kldlf@njmu.edu.cn

(Received: 19 January 2012;

Accepted: 28 December 2012)

AJC-12624

Convenient and efficient syntheses of 3-vinylphenyl ethyl (methyl) carbamate, one of potential metabolites from rivastigmine, has been developed. The overall yield is higher than $30 \%$ and represents the first direct synthesis of this metabolite from rivastigmine.

Key Words: Rivastigmine, Synthesis, Metabolite, Alzheimer's disease.

\section{INTRODUCTION}

Alzheimer's disease (AD) is the most common cause of progressive mental deterioration in people of advanced age. It is characterized by impaired neuronal signaling, leading to multiple cognitive deficits and often accompanied by behavioural disturbances ${ }^{1,2}$. Acetylcholine $(\mathrm{ACh})$ is the primary neurotransmitter that facilitates learning and increases attention.

The deficiency of acetylcholine is considered to be responsible for cognitive, behavioural and functional impairment ${ }^{3}$. Rivastigmine hydrogen tartrate (Exelon, 1), (S)-N-ethyl-3-[(1dimethylamino) ethyl]-N-methyl-phenyl carbamate hydrogen tartrate, is a reversible acetylcholinesterase inhibitor of the carbamate type approved for the treatment of alzheimer's disease $^{4}$. Rivastigmine was approved as cholinergic agent by many countries and regions including all the members of the European Union and the US ${ }^{5}$.

In pre-clinical and clinical studies, the metabolic mechanism and reaction of rivastigmine (1) have been studied in human. Analytical evaluation using liquid chromatographytandem mass spectrometry (LC-MS/MS) suggested that NAP 226-90 (2) and the potential metabolite, 3-vinylphenyl ethyl (methyl) carbamate (3) existed in human plasma ${ }^{6}$. Among them, the synthesis of $\mathbf{2}$ has been reported ${ }^{7}$. Rivastigmine is relatively a novel drug and perhaps for that particular reason, few synthesis methods of $\mathbf{3}$ have been reported in the literature. Prompt and convenient synthesis of $\mathbf{3}$ was required for an urgent request for providing the standard on quality control during drug production.<smiles>CCN(C)C(=O)Oc1cccc([C@@H](C)N(C)C)c1</smiles><smiles>C[C@H](c1cccc(O)c1)N(C)C</smiles><smiles>C=Cc1cccc(OC(=O)N(C)CC)c1</smiles>
3

Fig. 1. Rivastigmine (1), NAP 226-9 (2) and 3-vinylphenyl ethyl(methyl)carbamate (3)

In this paper, we report the highly efficient synthesis of $\mathbf{3}$ and the synthetic routes are described in Scheme-I. The target compound was synthesized by using ethyl(methyl)carbamic chloride (4) and 1-(3-hydroxyphenyl)ethanone (5) as the starting materials.

Preparation of 3-acetylphenyl ethyl(methyl)carbamate (6): Acetone $(150 \mathrm{~mL})$ was charged in a $250 \mathrm{~mL}$ three necked flask equipped with a reflux condenser and a mechanical stirrer. 5 (5 g, $36.76 \mathrm{mmol}$ ) was added with stirring at ambient temperature. $\mathrm{K}_{2} \mathrm{CO}_{3}(15 \mathrm{~g}, 108 \mathrm{mmol})$ was added in one lot. Then 4 (6.7 g, $55 \mathrm{mmol})$ was added dropwise in $15 \mathrm{~min}$. Then the mixture was refluxed for $3 \mathrm{~h}$. Cooled, filtered and evaporated in vacuum. The obtained mixture was dissolved in $\mathrm{CH}_{2} \mathrm{Cl}_{2}$ $(100 \mathrm{~mL})$. The organic phase was washed with $1 \mathrm{~N} \mathrm{NaOH}$ 
$(50 \mathrm{~mL} \times 2)$, brine and dried with $\mathrm{Na}_{2} \mathrm{SO}_{4}$. After evaporated in vacuum, $8.12 \mathrm{~g}$ of light yellow oil, 3-acetylphenyl ethyl (methyl)carbamate (6) was obtained in $99 \%$ yield ${ }^{8} .{ }^{1} \mathrm{H}$ NMR $\left(\mathrm{CDCl}_{3}, 400 \mathrm{MHz}, \mathrm{ppm}\right) \delta 7.78(\mathrm{~d}, 1 \mathrm{H}, J=7.7 \mathrm{~Hz}), 7.69$ (s, $1 \mathrm{H}), 7.45$ (t, 1H, $J=7.9 \mathrm{~Hz}), 7.34(\mathrm{~d}, 1 \mathrm{H}, J=8.0 \mathrm{~Hz}), 3.45$ (qd, $2 \mathrm{H}, J=7.1 \mathrm{~Hz}, J=18.5 \mathrm{~Hz}), 3.04(\mathrm{~d}, 3 \mathrm{H}, J=33.8 \mathrm{~Hz})$, $2.60(\mathrm{~s}, 3 \mathrm{H}), 1.23(\mathrm{td}, 3 \mathrm{H}, J=7.1 \mathrm{~Hz}, J=23.0 \mathrm{~Hz})$.

3-(1-Hydroxyethyl) phenyl ethyl(methyl)carbamate (7): $\mathrm{NaBH}_{4}(0.31 \mathrm{~g}, 8.2 \mathrm{mmol})$ was added to a cooled $\left(0{ }^{\circ} \mathrm{C}\right)$ solution of $6(3 \mathrm{~g}, 13.57 \mathrm{mmol})$ in dried EtOH $25 \mathrm{~mL}$ and then the resultant mixture was stirred for $1 \mathrm{~h}$ at room temperature. The reaction was quenched with saturated aqueous $\mathrm{NH}_{4} \mathrm{Cl}$ $(20 \mathrm{~mL})$ and then diluted with water $(50 \mathrm{~mL})$. The resultant solution was extracted with $\mathrm{CH}_{2} \mathrm{Cl}_{2}(30 \mathrm{~mL} \times 2 \mathrm{~mL})$ and the organic phase was washed with brine, dried and evaporated. $2.36 \mathrm{~g}$ of yellow oil, 3-(1-hydroxyethyl) phenyl ethyl (methyl) carbamate (7) was obtained, in $78 \%$ yield ${ }^{9}{ }^{1} \mathrm{H} \mathrm{NMR}\left(\mathrm{CDCl}_{3}\right.$, $400 \mathrm{MHz}, \mathrm{ppm}) \delta 7.33(\mathrm{t}, J=7.83 \mathrm{~Hz}, 1 \mathrm{H}), 7.20-7.15(\mathrm{~m}$, 2H), $7.02(\mathrm{~d}, J=7.77 \mathrm{~Hz}, 1 \mathrm{H}), 4.89$ (q, $J=6.48 \mathrm{~Hz}, 1 \mathrm{H})$, $3.51-3.38(\mathrm{~m}, 2 \mathrm{H}), 3.03(\mathrm{~d}, J=23.25 \mathrm{~Hz}, 3 \mathrm{H}), 1.49(\mathrm{~d}, J=$ $6.45 \mathrm{~Hz}, 3 \mathrm{H}), 1.27-1.17$ (m, 3H).

3-Vinylphenyl ethyl(methyl)carbamate (3): 7 (1.5 g, $6.7 \mathrm{mmol}$ ) was dissolved in $10 \mathrm{~mL}$ of pyridine and the solution was cooled to $0^{\circ} \mathrm{C}$ and then $\mathrm{TsCl}(1.92 \mathrm{~g}, 0.01 \mathrm{~mol})$ was added. The mixture was stirred at room temperature overnight. Then the mixture was evaporated in vacuum. The resultant was dissolved in 1,8-diazabicyclo [5.4.0] undec-7-ene (DBU, $5 \mathrm{~mL}$ ) and refluxed at $140{ }^{\circ} \mathrm{C}$ for $3 \mathrm{~h}$. After being cooled to room temperature, the reaction mixture was poured into ice-chilled EtOAc. The organic layer was washed with $1 \mathrm{~N} \mathrm{HCl} \mathrm{until} \mathrm{the}$ aqueous phase became less than $\mathrm{pH} 3$ then $5 \% \mathrm{NaHCO}_{3}$ and saturated $\mathrm{NaCl}$ three times, respectively and dried over $\mathrm{Na}_{2} \mathrm{SO}_{4}$. The residual yellow oil was purified by column chromatography on silica and $0.42 \mathrm{~g}$ of colourless oil 3 was obtained in $30 \%$ yield $^{10} .{ }^{1} \mathrm{H} \mathrm{NMR}\left(\mathrm{CDCl}_{3}, 400 \mathrm{MHz}, \mathrm{ppm}\right) \delta 7.29(\mathrm{t}, 1 \mathrm{H}$, $J=7.8 \mathrm{~Hz}), 7.21(\mathrm{~d}, 1 \mathrm{H}, J=7.7 \mathrm{~Hz}), 7.16(\mathrm{~s}, 1 \mathrm{H}), 7.01(\mathrm{~d}, 1 \mathrm{H}$, $J=7.8 \mathrm{~Hz}), 6.68(\mathrm{dd}, 1 \mathrm{H}, J=10.9 \mathrm{~Hz}, J=17.6 \mathrm{~Hz}), 5.73(\mathrm{dd}$, $1 \mathrm{H}, J=0.8 \mathrm{~Hz}, \mathrm{~J}=17.6 \mathrm{~Hz}), 5.25(\mathrm{dd}, 1 \mathrm{H}, J=0.6 \mathrm{~Hz}, J=10.9$ $\mathrm{Hz}), 3.43(\mathrm{~m}, 2 \mathrm{H}), 3.02(\mathrm{~d}, 3 \mathrm{H}, \mathrm{J}=29.4 \mathrm{~Hz}), 1.21(\mathrm{td}, 3 \mathrm{H}, J=$ 7.2Hz, $J=20.1 \mathrm{~Hz})$. ESI-MS m/z: $206.1[\mathrm{M}+\mathrm{H}]^{+}$.

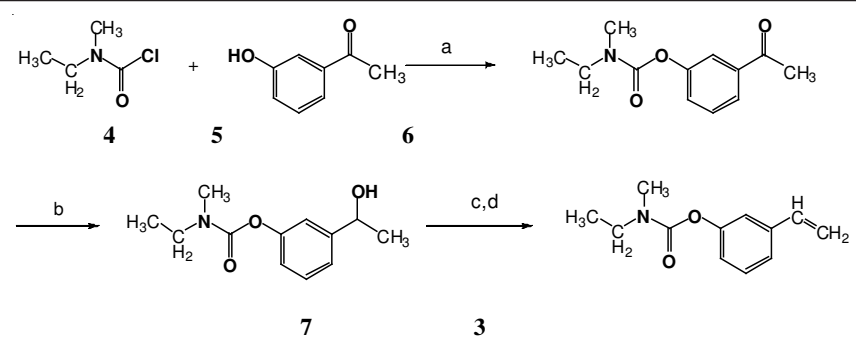

Scheme-I: $\quad$ Synthetic route of 3-vinylphenyl ethyl(methyl)carbamate (3). Reagents and conditions:(a) $\mathrm{K}_{2} \mathrm{CO}_{3}$, acetone; (b) $\mathrm{NaBH}_{4}$, $\mathrm{MeOH}$; (c) TsCl, Py; (d)DBU, reflux

\section{Conclusion}

An efficient synthetic approach is reported for the 3-vinylphenyl ethyl(methyl)carbamate in an overall yield $30 \%$ in three steps form the commercially available materials. With satisfactory yields and mild conditions, this route is able to be used a large scale to provide the standard samples of metabolite of rivastigmine.

\section{ACKNOWLEDGEMENTS}

The authors gratefully acknowledged the support of this work by the Natural Science Foundation of China (No. 21172108), Jiangsu Science and Technology Promotion Foundation (No. 08KJD310004) and NJMU Science and Technology Promotion Foundation (No. 06NMUM023) for the support.

\section{REFERENCES}

1. J.L. Cummings and G. Cole, J. Am. Med. Assoc., 287, 2335 (2002).

2. P.T. Francis, A.M. Palmer, M. Snape and G.K. Wilcock, J. Neurol. Neurosur. Psychiatry, 66, 137 (1999).

3. G. Lefèvre, M. Büche, G. Sedek, S. Maton, A. Enz, U. Lorch, C. Sagan and S. Appel-Dingemanse, J. Clin. Pharmacol., 49, 430 (2009).

4. B.R. Williams, A. Nazarians and M.A. Gill, Clin. Ther, 25, 1634 (2003).

5. J. Bhatt, G. Subbaiah and S. Kambli, J. Chromatogr. B, 852, 115 (2007).

6. F. Pommier and R. Frigola, J. Chromatogr. B, 784, 301 (2003).

7. F. Zhang, M. Hu, M. Xie, A. Lai, R. Sun, D. Chen, R. Bao and H. Bai, Prepatation Method of Rivastigmine, Its Intermediates and Preparation Method of the Intermediates, US Patent 0286437 A1 (2010).

8. A. Gaitonde and M. Mangle, GB Patent 2409453A.

9. F. Deng, J.J. Lu, H.Y. Liu, L.P. Lin, J. Ding and J.S. Zhang, Chin. Chem. Lett., 22, 28 (2011).

10. Y. Hayashi, S. Orikasa, K. Tanaka, K. Kanoh and Y. Kiso, J. Org. Chem., 65, 8402 (2000). 